\title{
Reimagining the U.S. Global Change Research Program to Support Equitable Community Engagement Using a Disability Lens
}

\section{Adria Schwarber}

American Institute of Physics, College Park, Maryland, USA

https://doi.org/10.38126/ISPG180307

Corresponding author: adria.schwarber@gmail.com

Keywords: USGCRP; climate equity and justice; disability lens; models of disability; universal design

Executive Summary: The U.S. Global Change Research Program (USGCRP or "the Program") is at a pivotal moment in its evolution as it works to develop its next decadal strategy. Constrained by an outdated mandate and facing an increasing demand for actional and usable climate information, the Program has an opportunity to re-envision its already robust participatory mechanisms to improve engagement with historically marginalized communities. The disability community is acutely sensitive to Earth's changing climate, facing threats from extreme weather, in addition to enhanced risks due to systematic ableism in our policy and planning spaces. However, the disability community can also be a critical source of innovative ideas and inclusive practices that can ensure the climate documents guiding future policy development are just and equitable. By adopting a disability lens in its strategy update plans, the Program can ensure that the climate information it provides to local and regional decisionmakers through the National Climate Assessment process supports future U.S. climate policy with the tenets of justice and equity at the core. In particular, the Program should revise its community engagement framework guided by 1) the social model of disability, 2) narratives from within the disability community, and 3) ideas of universal design.

\section{Introduction}

The consequences of anthropogenic climate change have historically been articulated by physical scientists focusing on its first-order impacts on our environment. In the mid-twentieth century-when the burgeoning field of climate science began to distinguish itself more clearly from physicsscientists tended to focus their research efforts on bounding the temperature increase we could expect from the continued rise of atmospheric greenhouse gas concentrations (Weart 2008).

The scientific discourse has since expanded to consider how climate change affects human systems, such as damaging infrastructure, stressing health care systems, fractionating cultural groups, etc. (IPCC 2014), as well as acknowledging the fundamental social justice and human rights issues critical to developing equitable climate change solutions. As the climate research community has grown, so should our policy mechanisms.

Nowhere is the need for evolution clearer than in the development of the U.S. National Climate Assessment (NCA), a Congressionally mandated report produced through the interagency U.S. Global Change Research Program (USGCRP or "the Program") that documents climate change in the U.S. (Global Change Research Act 1990). In its early years, USGCRP sought to advance understanding of the fundamental physics driving climate change, providing evidence to support the fact that humans have an outsized impact on Earth's climate.

Now, as the need for climate information has grown, USGCRP is outgrowing the bounds of its mandate, which requires that the Program produce a quadrennial assessment that: 
1. "integrates, evaluates, and interprets the findings of the Program and discusses the scientific uncertainties associated with such findings;

2. analyzes the effects of global change on the natural environment, agriculture, energy production and use, land and water resources, transportation, human health and welfare, human social systems, and biological diversity;

3. and analyzes current trends in global change, both human-induced and natural, and projects major trends for the subsequent twenty-five to 100 years" (Global Change Research Act 1990).

What is not included here is a call for the climate information presented in the NCA to be actionable or usable by local and regional decision-makers.

This year, USGCRP is at a crucial juncture as it works to update its decadal strategic plan, which will guide future climate assessment processes. In a National Academies of Sciences, Engineering, and Medicine (2021) assessment of the Program released in March 2021 as part of those revisioning steps, the Academies note that, "[g]iven the urgency of climate risks, the nation can no longer afford for the Program's historical interpretation of the U.S. Global Change Research Act (GCRA) to constrain efforts to build the capabilities needed to provide useful and usable information." Among those capabilities referenced in the report is the need for USGCRP to expand its support and integration of social science research within the NCA, particularly in the areas of equity and justice.

In order for the U.S. to build truly inclusive and equitable climate change solutions, the documents guiding decision makers in the development of those solutions must adopt more equitable and justiceoriented language and processes. My goal here is to concentrate on this recommendation and discuss the needs of one of the most diverse social identity groups: the disability community (defined in Section III). More specifically, I propose that the Program embrace a disability lens in its work by adopting a revised community engagement framework guided by 1 ) the social model of disability, 2) narratives from within the disability community, and 3 ) ideas of universal design.

\section{Scoping the impact}

Worldwide more than one billion people, or $15 \%$ of the population, are estimated to live with some form of disability-making the disability community the "largest minority in the world" (World Health Organization 2011). In the U.S., where the basic rights and dignities of people with disabilities are codified into law (e.g., Section 504 of the Rehabilitation Act, Americans with Disability Act), one in four Americans reported a disability in 2016, totaling more than 61 million people (Okoro 2018), though that number is likely much larger (Komaroff 2020).

As a social identity group, disability is also highly intersectional and is present among all other marginalized identities including race, gender, and age (Crenshaw 1989; Goethals, De Schauwer, and Van Hove 2015; Brown and Moloney 2019; Frederick and Shifrer 2019). Disability may be considered only one part of an individual's identity, but can underpin many interactions with society, even if it is not the dominant identity group facing marginalization (Erevelles and Minear 2010; Shaw 2012).

For the disability community-often placed at the intersection of inequity and climate risk exposureinclusion in disaster management and climate planning discourses can mean the difference between life and death (Serna 2019). This dynamic was laid bare during the 2019 and 2020 California wildfires as individuals in the disability community were left to navigate inaccessible evacuation plans without support (Vasquez 2021), manage mental health in the face of uncertainty (LaFee 2021), or cope with planned power shut-offs from utilities-public safety power shut-offs-which stranded wheelchair users and others who rely on medical devices to survive (Orenstein 2019; Har 2019).

Despite such representation and need, the disability community is often omitted from climate policy frameworks and planning (Wilson 2017). As the world grapples with devastating climate impacts, including increased risks of extreme weather events, droughts, and wildfires, USGCRP needs to hear the voices of the disability community and expand upon potential solutions by examining how the disability community has already navigated an inaccessible and changing world (Twigg et al. 2018; Wolbring 2009). 


\section{Understanding disability}

\section{i. Disability in governance frameworks}

Internationally, the fundamental rights of people with disabilities are codified through the United Nations Convention on the Rights of Persons with Disabilities, which came into force in 2008. Though the Convention does not explicitly delineate rights in the face of climate change, Article 11 states that parties shall take "all necessary measures to ensure the protection and safety of persons with disabilities in situations of risk, including situations of armed conflict, humanitarian emergencies and the occurrence of natural disasters" (Márton et al. 2013).

Language in the Cancun Agreement, which was adopted at a United Nations Framework Convention on Climate Change meeting in December 2010, further identified persons with disabilities as one of the segments of the population whose human rights are acutely affected by the impacts of climate change (UNFCCC 2011). However, the majority of international climate frameworks and documents amalgamate the disability community within other 'vulnerable groups,' rather than delineating the dynamic needs of specific populations and the ways in which disability can spark innovative practices.

One can find this vague language in the most recent iteration of the Intergovernmental Panel on Climate Change report (IPCC 2014) and the Preamble to the Paris Agreement (UNFCCC 2015). It would come as no surprise that the NCA is guilty of this as well, and the four instances in which the word 'disability(ies)' appears in the fourth climate assessment are used within this context (USGCRP 2018).

\section{ii. Medical model of disability}

Grouping the disability community within "vulnerable groups" places an over-reliance on the medical definition of disability. In the medical model, disability is viewed as a deficiency or abnormality in need of a "cure" or "normalization," and places the responsibility for navigating society with the individual who is experiencing the disability (Shaw 2012). Critical disability theory (Hall 2019) further differentiates disability from an impairment, which is defined as "lacking part of or all of a limb, or having a defective limb, organ or mechanism of the body," and does not necessarily imply a positive or negative value judgment (Oliver 2009). iii. Social model of disability

By contrast, the social model of disability posits that disability itself is a result of environmental barriers, social structures, and negative attitudes limiting an individual's full participation in society (Goering 2015; Shaw 2012). For example, Goering (2015) notes that "[p]eople who are blind from birth, for instance, often understand their blindness as a neutral way of being, rather than as a deficit or a problem," and continues that they may only suffer negative reactions to their impairment because society has marginalized them.

Misplaced use of the medical model of disability ignores the power and potential solutions that could arise from not only integrating disabled voices more meaningfully into engagement processes, but also from developing policies with a disability lens in mind (Twigg et al. 2018; Serrato Marks and Bayer 2019). As an example, we can look to the concept of "deaf gain," which refers to the valuable perspectives and innovations D/deaf and hard-of-hearing people provide because of their differences (Bauman and Murray 2014). Cooke (2018) noted that her deaf gain is reflected in her "intensely visual" geoscience research, which ultimately allows the figures in her papers to tell the scientific story, rather than relying solely on descriptions.

Instead of focusing on deficit language in the NCA, the Program should embrace the social model of disability to overcome the unnecessary political, social, and attitudinal barriers that have limited the full participation of disabled voices in its processes. The result would be a more inclusive resource that decision-makers can use to inform the development of just climate solutions.

\section{Hearing disability voices}

In reducing barriers to participation by considering the social model of disability, USGCRP can also more readily recognize the disability rights adage, "nothing about us without us," (Charlton 1998) and undertake transformative mechanisms to support greater participation and integration of the knowledge of the disability community in defining research questions or adopting governance frameworks (Bell, Tabe, and Bell 2020).

For instance, USGCRP should envision an iterative community engagement framework that extends 
beyond user-defined research and considers peopleinspired, co-developed research questions. The disability community, advocacy groups, and scientists with disabilities should be involved in developing the fundamental research questions that drive the development of the NCA and its eventual application to the policy space.

It is also important that USGCRP understand, however, that the disability community is not a monolith. Disabilities can vary over time and in severity, and include a range of physical, mental, or intellectual impairments that can be visible or invisible, temporary or chronic. Including a diversity of voices, experiences, and perspectives, therefore, is vital, but this work should not be tokenistic or overburden scientists with disabilities (Frias, Segarra, and Serrato Marks 2021).

In this area, literature can be a useful resource. Outside of academic publications in journals related to disabilities (e.g., Disability Studies Quarterly, Society and Disability, American Annals of the Deaf, etc.), there is extensive grey literature on the experiences of the disability community in the U.S. and elsewhere. In general, grey literature often takes the form of narratives (e.g., Orenstien 2019, Serrato Marks and Bayer 2019), interviews and oral histories (e.g., Wong 2020), or memoirs (e.g., Heumann 2020), among other resources.

When developing its decadal strategy and considering changes to its community engagement frameworks and policies, USGCRP should seek out academic papers as well as grey literature discussing disability in the context of climate change, disaster management and planning, and eco-ableism.

The Program should also ensure that citations of literature are not used in place of physical representation in decision-making spaces. There are numerous government-based resources the Program can leverage, including the National Council on Disability, and many disability nonprofits and nongovernmental organizations with expertise in disability rights across the issue spectrum (e.g., Association of University Centers on Disabilities, Autistic Self Advocacy Network, American Association of People with Disabilities, etc.), including those with Earth and climate science practitioners (e.g., International Association for
Geoscience Diversity, International Disability Alliance, etc.)

\section{Implementing aspects of universal design}

The USGCRP can also employ universal design, the concept that products and environments be intentionally designed to maximize usability by people of all ages and abilities to the greatest extent possible (National Disability Authority 2020), to develop a community engagement mechanism more readily accessible to everyone. Originally conceived to focus on the built environment (Story 1998), universal design has been adopted in other contexts (education, technology) to ensure information or services are accessible, usable, and attainable by everyone without further accommodations. It consists of several principles including equitable use, flexibility in use, and minimizing adverse consequences.

A straightforward example of universal design is captioning or transcription. Though providing interpreting or captioning services for $\mathrm{D} /$ deaf and hard-of-hearing individuals is mandated by law in the U.S., the use of captions and transcripts has become prolific across all of society. Captions improve access to information across a diverse set of situations. For example, people use captions when watching television in a noisy room or when attending a presentation in a different language.

A more updated definition that follows the same principles but is more applicable to the NCA states that universal design is, "a process that enables and empowers a diverse population by improving human performance, health and wellness, and social participation" (Steinfeld and Maisel 2012). Within both the NCA process and development of the USGCRP's next decadal strategy, community engagement process could employ universal design principles using a simple thought experiment. For example, questions could be asked: Does the community feedback framework adopt a social model of disability and thus aim to structure processes to ensure universal access? What innovations could we employ to gather feedback from the most diverse communities without overburdening them? Would adopting a particular engagement strategy create unintended consequences for people with disabilities and other historically marginalized communities? 
The development of what questions USGCRP should be asking to ensure universal design principles are met could be informed via stakeholder engagement with the disability community. However, some mechanisms in the public input process are outside the control of the Program, mainly the opaque Federal Register system agencies use to solicit public information or feedback. There are many other existing resources the Program can more quickly leverage, including the resources discussed in section IV of this work. The toolkits and resources provided by the Centre for Excellence in Universal Design (2020) are another such example that can guide the Program's implementation of universal design principles in various forms of communication. For example, one of its toolkits provides scenarios for energy companies to improve written communication and engagement with customers using universal design, with recommendations on font choices, avoiding jargon, and conveying information through both images and text, among others.

\section{Conclusion}

Climate change is inherently inequitable, disproportionately impacting historically marginalized groups by amplifying risks for communities already coping with other physical, political, or socioeconomic stressors. While the disability community may be particularly vulnerable to climate impacts, they can also be a source of innovative and inclusive methods for expanding participatory processes in the climate policy arena. Incorporating ideas of the social model of disability, embracing "nothing about us without us," and implementing universal design principles-all aspects of viewing work through a disability lenscan make our climate governance documents and subsequent climate policies more just and equitable. For the USGCRP, which is at an important juncture in its evolution, re-envisioning its next 10 years using a disability lens can support more equitable and inclusive climate policies and planning practices.

\section{References}

Bauman, Dirksen, and Joseph J. Murray. 2014. "An Introduction to Deaf Gain." Psychology Today. Sussex Publishers, November 13, 2014. https://www.psychologytoday.com/us/blog/dea f-gain/201411/introduction-deaf-gain.

Bell, Sarah L., Tammy Tabe, and Stephen Bell. 2020. "Seeking a disability lens within climate change migration discourses, policies and practices." Disability and Society 35 (4) 682-687. https://doi.org/10.1080/09687599.2019.16558 $\underline{56}$.

Brown, Robyn Lewis, and Mairead Eastin Moloney. 2019. "Intersectionality, Work, and Well-Being: The Effects of Gender and Disability." Gender \& Society 33, no. 1 (February 2019): 94-122. https://doi.org/10.1177/0891243218800636.

Centre for Excellence in Universal Design. 2020. "Customer Engagement in Energy Services.” Accessed June 18, 2021.

http://universaldesign.ie/productsservices/customer-engagement-in-energyservices/.

Charlton, James I. 1998. "Nothing About Us Without Us." In Nothing About Us Without Us: Disability Oppression and Empowerment, 3-18. University of California Press, 1998. Accessed June 18, 2021. http://www.jstor.org/stable/10.1525/j.ctt1pnqn 9.6.
Cooke, Michele. 2018. "What Is My Deaf Way of Science?" UMass Magazine. UMass University Communications, November 5, 2018. https://www.umass.edu/magazine/fall2018/what-my-deaf-way-science.

Crenshaw, Kimberle. 1989. "Demarginalizing the Intersection of Race and Sex: A Black Feminist Critique of Antidiscrimination Doctrine, Feminist Theory and Antiracist Politics," University of Chicago Legal Forum: Vol. 1989, Article 8. https://doi.org/10.4324/9780429500480-5.

Erevelles, Nirmala, and Andrea Minear. 2010. "Unspeakable Offenses: Untangling Race and Disability in Discourses of Intersectionality." Journal of Literary \& Cultural Disability Studies 4, no. 2 (2010): 127-145. https://muse.jhu.edu/article/390395.

Frias, Daphne, Annie Segarra, and Gabi Serrato Marks. 2021. "Disability Justice, Climate Change and EcoAbleism." Earth Institute, April 8, 2021. https://www.earth.columbia.edu/videos/view/d isability-justice-climate-change-and-eco-ableism.

Frederick, Angela, and Dara Shifrer. 2019. "Race and disability: From analogy to intersectionality." Sociology of Race and Ethnicity 5, no. 2 (2019): 200-214.

https://doi.org/10.1177/2332649218783480. 
Global Change Research Act of 1990, Public Law 101-606. 1990. 104 Stat. 3096-3104, November 16, 1990. https://www.govinfo.gov/content/pkg/STATUT E-104/pdf/STATUTE-104-Pg3096.pdf.

Goering, Sara. 2015. "Rethinking disability: the social model of disability and chronic disease." Current reviews in musculoskeletal medicine 8 , no. 2 (2015): 134-138. https://doi.org/10.1007/s12178-015-9273-z.

Goethals, Tina, Elisabeth De Schauwer, and Geert Van Hove. 2015. "Weaving Intersectionality into Disability Studies Research: Inclusion, Reflexivity and AntiEssentialism." DiGeSt. Journal of Diversity and Gender Studies 2, no. 1-2 (2015): 75-94.

https://doi.org/10.11116/jdivegendstud.2.1$\underline{2.0075}$.

Hall, Melinda C. 2019. "Critical Disability Theory", The Stanford Encyclopedia of Philosophy (Winter 2019 Edition), Edward N. Zalta (ed.), https://plato.stanford.edu/archives/win2019/en tries/disability-critical/.

Har, Janie. 2019. "Wildfire Power Shutoffs Leave the Disabled in Darkness and Danger: 'You Couldn't See in Front of You'." USA Today, Gannett Satellite Information Network, 1 Nov. 2019, www.usatoday.com/story/news/2019/10/31/ca lifornia-fires-pg-e-power-shutoffs-leave-elderlydisabled-dark/4108318002/.

Heumann, Judith. 2020. "Being Heumann Large Print Edition: An Unrepentant Memoir of a Disability Rights Activist." Beacon Press, 2020.

http://www.beacon.org/Being-HeumannP1553.aspx.

International Disability Alliance. 2020. "Disability Inclusive Climate Action." 2020. www.internationaldisabilityalliance.org/climatechange.

IPCC. 2014. "Climate Change 2014: Synthesis Report. Contribution of Working Groups I, II and III to the Fifth Assessment Report of the Intergovernmental Panel on Climate Change" [Core Writing Team, R.K. Pachauri and L.A. Meyer (eds.)]. IPCC, Geneva, Switzerland, $151 \mathrm{pp}$.

https://www.ipcc.ch/site/assets/uploads/2018/ 05/SYR AR5 FINAL full wcover.pdf.

Komaroff, Anthony. 2020. "The Tragedy of the Post-COVID 'Long Haulers.'" Harvard Health Blog, 30 Oct. 2020. www.health.harvard.edu/blog/the-tragedy-ofthe-post-covid-long-haulers-2020101521173.

LaFee, Scott. 2021. "Poorer Mental Health Smolders After Deadly, Devastating Wildfire." UC San Diego Health (2021).

https://health.ucsd.edu/news/releases/Pages/2 021-02-09-poorer-mental-health-smolders-afterdeadly-devastating-wildfire.aspx.
Márton, Sándor Mészáros, Gergely Polk, and Disability Rights Center Fiala. 2013. "Convention on the Rights of Persons with Disabilities." USA: United Nations (2013).

https://www.un.org/development/desa/disabili ties/convention-on-the-rights-of-persons-withdisabilities/convention-on-the-rights-of-personswith-disabilities-2.html.

Mégret, Frédéric. 2008. "The Disabilities Convention: Human Rights of Persons with Disabilities or Disability Rights?" Human Rights Quarterly 30, no. 2 (2008): 494-516. Accessed June 21, 2021. http://www.jstor.org/stable/20072851.

National Academies of Sciences, Engineering, and Medicine. 2021. Global Change Research Needs and Opportunities for 2022-2031. Washington, DC: The National Academies Press. https://doi.org/10.17226/26055.

National Disability Authority. 2020. "What Is Universal Design." Centre for Excellence in Universal Design, 2020.

http://universaldesign.ie/What-is-UniversalDesign/.

Okoro CA, Hollis ND, Cyrus AC, Griffin-Blake S. 2018. "Prevalence of Disabilities and Health Care Access by Disability Status and Type Among Adults United States, 2016." MMWR Morb Mortal Wkly Rep 2018; 67:882-887. http://dx.doi.org/10.15585/mmwr.mm6732a3.

Oliver, Michael. 2009. Understanding disability: From theory to practice. Macmillan International Higher Education, 2009. https://doi.org/10.1007/978-1-349-24269-6.

Orenstein, Natalie. 2019. "Berkeley Residents with Disabilities Say Their Needs 'Not Built into' PG\&E Shutoff Policy." Berkeleyside, 18 Nov. 2019, www.berkeleyside.com/2019/11/05/berkeleyresidents-with-disabilities-say-their-needs-notbuilt-into-pge-shutoff-policy.

Serrato Marks, Gabi, and Skylar Bayer. 2019. "Our Disabilities Have Made Us Better Scientists." Scientific American Blog Network. Scientific American, July 2019. https://blogs.scientificamerican.com/voices/our -disabilities-have-made-us-better-scientists/.

Serna, Joseph. 2019. "California Disaster Planning Continues to Forget People with Disabilities, Audit Finds." Los Angeles Times, Los Angeles Times, 22 Dec. 2019, www.latimes.com/california/story/2019-12$\underline{22 / \text { california-natural-disaster-audit-vulnerable- }}$ citizens-wildfires. 
Shaw, Linda R., Fong Chan, and Brian T. McMahon. 2012. "Intersectionality and Disability Harassment: The Interactive Effects of Disability, Race, Age, and Gender." Rehabilitation Counseling Bulletin 55, no. 2 (January 2012): 82-91. https://doi.org/10.1177/0034355211431167.

Smith, F., M. Simard, and J. Twigg. 2017. "Disability and climate resilience: a literature review." London: Leonard Cheshire (2017). https://www.researchgate.net/publication/3208 00956 Disability and Climate Resilience A litera ture review.

Story, Molly Follette, James L. Mueller, and Ronald L. Mace. 1998. "The universal design file: Designing for people of all ages and abilities." (1998). https://eric.ed.gov/?id=ED460554.

Twigg, John, Emma Lovell, and Maria Kett. 2018. "Disability inclusion and disaster risk reduction: Overcoming barriers to progress." (2018). http://cdn.odi.org/media/documents/12324.pdf. UNFCCC. 2011. "Decision 1/CP. 16, The Cancun Agreements: Outcome of the work of the Ad Hoc Working Group on long-term Cooperative Action under the Convention." In Report of the Conference of the Parties on its sixteenth session, Addendum, Part Two: Action taken by the Conference of the Parties. https://unfccc.int/documents/6527.

UNFCCC. 2015. "Paris Agreement to the United Nations Framework Convention on Climate Change," T.I.A.S. No. 16-1104.

https://unfccc.int/sites/default/files/english par is agreement.pdf.
USGCRP. 2018. "Impacts, Risks, and Adaptation in the United States: Fourth National Climate Assessment, Volume II" [Reidmiller, D.R., C.W. Avery, D.R. Easterling, K.E. Kunkel, K.L.M. Lewis, T.K. Maycock, and B.C. Stewart (eds.)]. U.S. Global Change Research Program, Washington, DC, USA, 1515 pp. https://doi.org/10.7930/NCA4.2018.

Vasquez, Krystal. 2021. "A Disability Should Not Be a Death Sentence during a Natural Disaster." EHN. EHN, April 28, 2021.

https://www.ehn.org/natural-disastersdisabled-community-2652503611.html.

Weart, Spencer. 2008. The Discovery of Global Warming A History. https://history.aip.org/climate/index.htm.

Wilson, Kate. 2017. "Voices of People with Disabilities Must Be Heard in Climate Change Adaptation Debate." International Institute for Environment and Development, 30 Jan. 2017, www.iied.org/voicespeople-disabilities-must-be-heard-climatechange-adaptation-debate.

Wolbring, G. 2009. "A Culture of Neglect: Climate Discourse and Disabled People" M/C Journal, 12(4). https://doi.org/10.5204/mcj.173.

Wong, Alice. 2020. The Disability Visibility Project. Podcast audio, 2020. https://disabilityvisibilityproject.com/podcast2/.

World Health Organization. 2011. "World report on disability 2011." 2011.

https://www.who.int/disabilities/world report/ 2011/report.pdf.

Adria Schwarber is a climate scientist working in science policy. She is currently an analyst with FYI: Science Policy News at the American Institute of Physics, where she reports on science policy developments and creates actionable resources for the physical sciences community. Originally from Kentucky, she earned her Ph.D. in atmospheric and oceanic science from the University of Maryland, College Park.

\section{Acknowledgements}

The author would like to acknowledge the contributions of Krystal Vasquez, Ph.D. Candidate at the California Institute of Technology, and Valerie Novack, Disability Policy Fellow at Center for American Progress, in the formulation of an earlier version of this manuscript. The author would also like to acknowledge Alex Ghenis, Director of Accessible Climate Strategies, for helping in the ideation phase of the writing process.

\section{Disclaimer}

The ideas expressed in this manuscript are that of the author alone and do not necessarily represent the view of any previous, current, or future employer. The author has no conflicts of interest to disclose. This manuscript did not receive any funding from any sources. 